Jurnal Inkofar * Volume 1 No. 1 Juli 2019 * ISSN: 2615-3645 (Print) / 2581-2920 (Online)

Tersedia secara online di: http://www.politeknikmeta.ac.id/meta/ojs/

\title{
IMPLEMENTASI APLIKASI KOPERASI SIMPAN PINJAM DESA CIKAMPAK BERBASIS WEB
}

\author{
Romindo ${ }^{1}$, Nur Aisyah ${ }^{2}$ \\ ${ }^{1}$ Manajemen Informatika / Politeknik Ganesha / romindo4@gmail.com \\ ${ }^{2}$ Manajemen Informatika / Politeknik Ganesha / nur27902aisyah@gmail.com
}

\begin{abstract}
Savings and Loans Cooperative Karya Murni Desa Cikampak is a cooperative that provides savings and loan services to the surrounding community, especially the Cikampak village. The existing system at the Cikampak Village Savings and Loan Cooperative still uses manual methods, which are based on written records which are then entered into Microsoft Excel, which are still less effective in making reports on cooperatives. To improve services for the Savings and Loan Cooperative in Karya Desa Cikampak, it is better for better data handling and processing. Therefore, the researchers tried to make the application a solution to overcome this problem. The application implemented is web-based with the PHP programming language and MySQL database, because by using this software, researchers hope that the application implemented will be more effective than the old system. The purpose of this study is to facilitate employees in the process of entering data, so that they can work quickly, precisely, accurately and without human error. To obtain data that is in accordance with this study, the authors conducted a method of field research and library research.
\end{abstract}

Keywords: Savings and Loans Cooperative, PHP, Mysql

\begin{abstract}
ABSTRAK
Koperasi Simpan Pinjam Karya Murni Desa Cikampak adalah sebuah koperasi yang memberikan pelayanan berupa simpan pinjam kepada masyarakat sekitar, khususnya desa Cikampak. Sistem yang ada pada Koperasi Simpan Pinjam Desa Cikampak masih menggunakan cara yang manual, yaitu berdasarkan pada catatan tertulis yang kemudian di input ke Microsoft Excel, yang mana masih kurang efektif dalam membuat laporan pada koperasi tersebut. Untuk meningkatkan pelayanan pada Koperasi Simpan Pinjam Karya Murni Desa Cikampak menjadi lebih baik maka dibutuhkan suatu penanganan dan pengolahan data yang lebih baik. Maka dari itu peneliti mencoba membuat sebuah aplikasi sebagai solusi untuk mengatasi masalah tersebut. Aplikasi yang diterapkan berbasiskan web dengan bahasa pemrograman PHP dan database MySQL, karena dengan menggunakan software ini, peneliti berharap aplikasi yang diterapkan akan menjadi lebih efektif dibandingkan dengan sistem yang lama. Tujuan penelitian ini adalah untuk memudahkan karyawan dalam proses menginput data, agar dapat bekerja dengan cepat, tepat, akurat dan tanpa human error. Untuk mendapatkan data yang sesuai dengan penelitian ini, peneliti melakukan metode penelitian lapangan dan penelitian
\end{abstract} kepustakaan.

Kata Kunci: Koperasi Simpan Pinjam, PHP, Mysql

\section{PENDAHULUAN}

Pada zaman yang serba canggih ini, komputer telah menjadi bagian terpenting dalam kehidupan masyarakat. Begitu pula dengan penggunaan internet. Hampir semua masyarakat telah menggunakan komputer dan internet dalam menyelesaikan pekerjaannya. Komputer mempermudah penggunanya dalam menyelesaikan pekerjaan yang sulit dan butuh ketelitian, maka dengan bantuan komputer tersebut dapat mengurangi kesalahan, keterlambatan kerja dan human error.

Penelitian sebelumnya yang mengangkat tentang koperasi simpan pinjam dilakukan oleh Dani Anggoro pada tahun 2015 dengan judul: "Rancangan Sistem Informasi Koperasi Simpan Pinjam Guru Dan Pegawai Pada Koperasi SMK Manggala”. Penelitian ini bertujuan membangun sistem informasi yang akan mendukung ketepatan data sehingga meningkatan kualitas dalam pelayanan simpan pinjam. Penelitian selanjutnya dilakukan oleh Wanti Simanjuntak pada tahun 2017 dengan judul: "Perancangan Sistem Informasi Simpan Pinjam Pada Koperasi Karyawan Jujur Makmur". Penelitian ini bertujuan membangun sistem yang mempermudah pengurus koperasi dalam melakukan 
pengolahan data koperasi sehingga meningkatkan kinerja pengurus koperasi agar lebih efisien dan meninimalkan kesalahan dalam pengolahan data koperasi.

Koperasi simpan pinjam Karya Murni desa Cikampak adalah instansi yang mengurus masalah simpan pinjam yang masih menggunakan cara manual dalam mengolah data dan menghasilkan laporanlaporan yang dibutuhkan. Sistem yang diterapkan pada koperasi simpan pinjam ini yaitu berdasarkan pada catatan tertulis oleh pengurus koperasi, yang kemudian di input pada Microsoft Excel, yang mana masih kurang efektif dalam pembuatan laporan pada koperasi tersebut.

Berdasarkan permasalahan yang ada maka peneliti tertarik mengangkat judul penelitian "Perancangan Aplikasi Koperasi Simpan Pinjam Desa Cikampak Berbasis Web". Aplikasi yang dibangun ini diharapkan dapat mengatasi permasalahan pada pengolahan data pada koperasi simpan pinjam desa Cikampak, sehingga pengolahan data dan penyampaian informasi menjadi lebih efektif dan mudah.

\section{LANDASAN TEORI}

\subsection{PERANCANGAN APLIKASI}

Kristanto (2013:61) menyatakan bahwa perancangan aplikasi adalah suatu fase dimana diperlukan suatu keahlian perancangan untuk elemen-elemen komputer yang akan menggunakan aplikasi, yaitu pemilihan peralatan dan program komputer untuk sistem yang baru.

Tujuan perancangan menurut Darmawan (2013:228) yaitu:

1. Memenuhi kebutuhan pemakaian sistem (user).

2. Memberikan gambaran yang jelas dan menghasilkan rancang bangun yang lengkap kepada pemrograman komputer dan ahli-ahli teknik lainnya yang terlibat dalam pengembangan atau pembuatan sistem secara rinci.

\subsection{Koperasi}

Menurut UU No. 17 Tahun 2012 koperasi aalah badan hukum yang didirikan oleh orang, perseorangan atau badan hukum koperasi dengan pemisahan kekayaan para anggotanya sebagai modal menjalankan usaha, yang memenuhi aspirasi dan kebutuhan bersama dibidang ekonomi, sosial, dan budaya sesuai dengan nilai dan prinsip koperasi.

Macam-macam koperasi:

1. Koperasi berdasarkan jenis usahanya

a. Koperasi Simpan Pinjam (KSP)

b. Koperasi Serba Usaha (KSU)

c. Koperasi Konsumsi

d. Koperasi Produksi

2. Koperasi berdasarkan keanggotaannya

a. Koperasi Petani

b. Koperasi Pensiunan

c. Koperasi Pegawai Republik Indonesia

d. Koperasi Sekolah

e. Koperasi Unit Desa (KUD)

f. Koperasi Pasar (Koppas)

3. Koperasi berdasarkan tingkatannya
a. Koperasi Primer

b. Koperasi Sekunder

\subsection{Koperasi Simpan Pinjam}

Menurut UU Nomor 17 Tahun 2012 Pasal 1 koperasi simpan pinjam adalah koperasi yang menjalankan usaha simpan pinjam sebagai satu-satunya usaha. Sumber modal koperasi simpan pinjam berasal ari simpanan pokok, simpanan wajib, dan donasi atau hibah. Tujuan koperasi simpan pinjam yaitu mengembangkan kesejahteraan anggota pada khususnya, dan masyarakat pada umumnya.

\subsection{Website}

Website adalah kumpulan dari berbagai macam halaman situs yang terangkum didalam sebuah domain atau subdomain yang berada didalam $W W W$ dan tentunya terdapat didalam internet. Jenisjenis website menurut Ippho Santoso dalam Rahmadi (2013:1) adalah website statis dan website dinamis. 


\subsection{PHP (Hypertext Preprocessor)}

Menurut Sidik (2014:4) menyatakan bahwa PHP dikenal sebagai pemrograman script-script yang membuat dokumen HTML secara on the fly yang dieksekusi di server web, yang dihasilkan dari suatu aplikasi bukan dokumen HTML. Tipe data pada PHP adalah integer, float, string, boolean, array.

\subsection{Database}

Menurut Rosa Shalahuddin (2015:43) basis data adalah sistem yang terkomputerisasi yang tujuan utamanya adalah memelihara data yang sudah diolah atau diinformasikan dan membuat informasi tersedia saat dibutuhkan. Fungsi database adalah:

1. Mengelompokan data agar mudah dipahami.

2. Menghindari duplikasi data dan inkonsistensi data.

3. Membuat mudah dalam menyimpan, mengakses, memperbarui dan menghapus data.

\subsection{PHP MyAdmin}

Menurut Buana (2014:2) PHP MyAdmin adalah salah satu aplikasi yang diguakan untuk memudahkan dalam melakukan pengelolaan database MySQL yang bersifat open ource.

\subsection{MySQL}

Madcoms (2016:17) menyatakan bahwa MySQL adalah sistem manajemen database SQL yang bersifat open source dan paling popular saat ini. Sistem database MySQL mendukung beberapa fitur seperti multithreaded, multi user, dan SQL Database Management System (DBMS).

\section{METODE PENELITIAN}

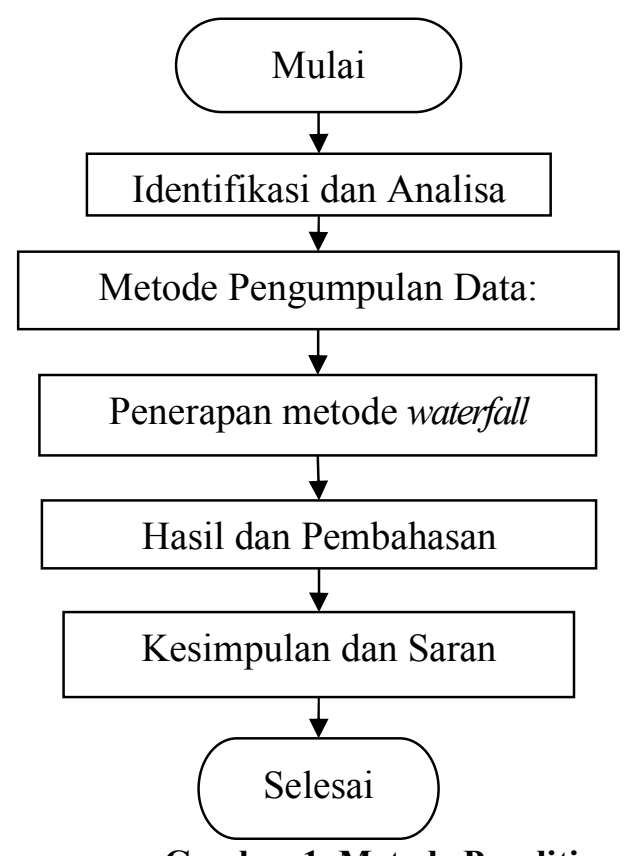

\section{ANALISA DAN PEMBAHASAN}

\subsection{Analisa Sistem yang sedang Berjalan}

Dari analisis sistem yang sedang berjalan pada koperasi simpan pinjam Karya Murni desa Cikampak maka dapat dilihat bahwa proses penginputan data masih dilakukan secara manual, dimana setiap petugas akan menginput data nasabah, data simpanan, data pinjaman dan laporan dengan cara menuliskan data tersebut kedalam buku besar.

Kendala-kendala yang dihadapi oleh sistem yang sedang berjalan:

1. Sistem pencatatan data yang digunakan selama ini dapat mengalami kesalahan penulisan.

2. Dalam membuat laporan transaksi yang terjadi pada koperasi ini memakan waktu lama. 


\subsection{Perancangan Sistem}

1. Use Case Diagram

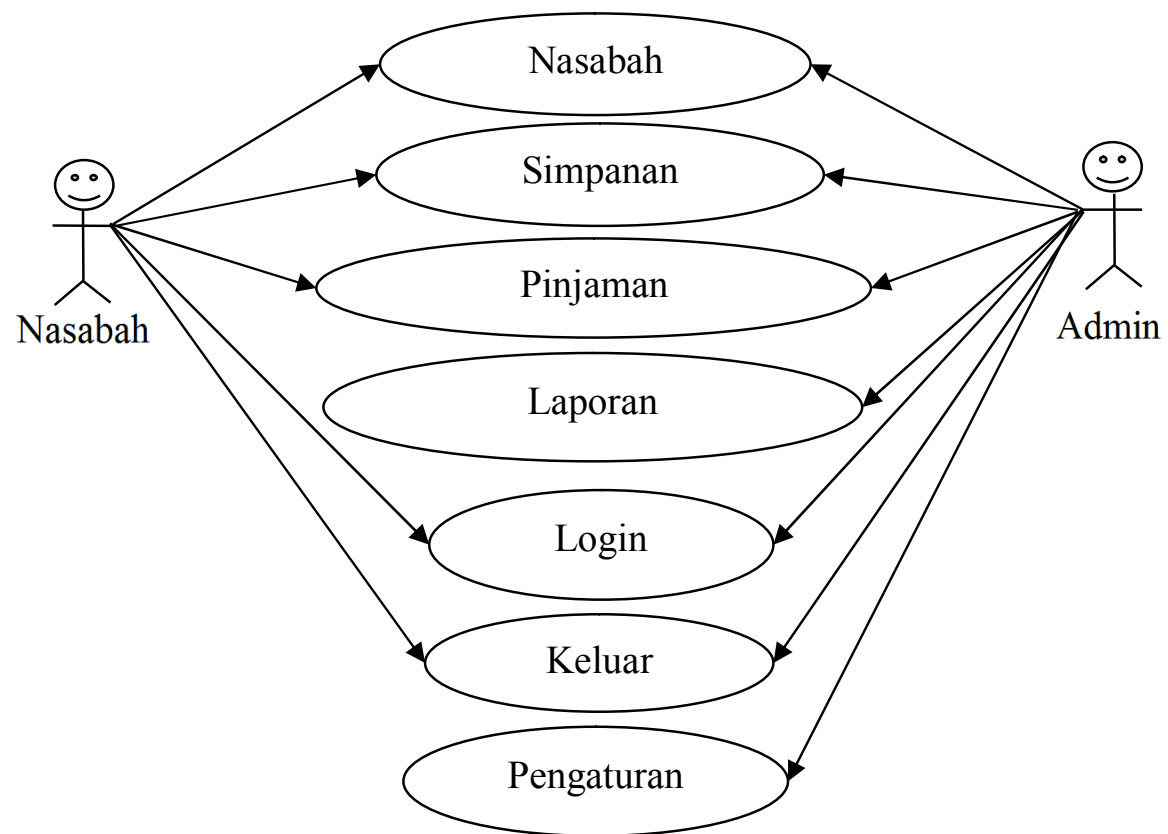

Gambar 2. Use Case Diagram

1. Nama use case : Nasabah

Actor : Nasabah dan Admin

Tujuan : Menambah data nasabah

Deskripsi : Nasabah dan admin dapat menambahkan data nasabah pada sistem informasi dengan menggunakan form data nasabah.

2. Nama use case : Simpanan

Actor

: Nasabah dan Admin

Tujuan

: Menambah data simpanan

Deskripsi

: Nasabah dan Admin dapat menambah data simpanan untuk dapat mengakses sistem informasi.

3. Nama use case : Laporan

Actor : : Admin

Tujuan : Menambah data laporan

Deskripsi : Admin sebagai user dapat menambah data laporan melalui form data laporan.

5. Nama use case : Login

Actor

: Nasabah dan Admin

Tujuan

: Verifikasi User

Deskripsi

: Sistem akan meminta user untuk memasukkan username dan password ke dalam form login agar dapat mengakses sistem informasi tersebut

6. Nama use case : keluar/logout

Actor : Nasabah dan admin

Tujuan : Keluar dari sistem informasi

Deskripsi $\quad$ : Nasabah dan admin sebagai user dapat keluar dari sistem setelah login. 
Jurnal Inkofar * Volume 1 No. 1 Juli 2019 * ISSN: 2615-3645 (Print) / 2581-2920 (Online)

Tersedia secara online di: http://www.politeknikmeta.ac.id/meta/ojs/

2. Flowchart sistem yang diusulkan

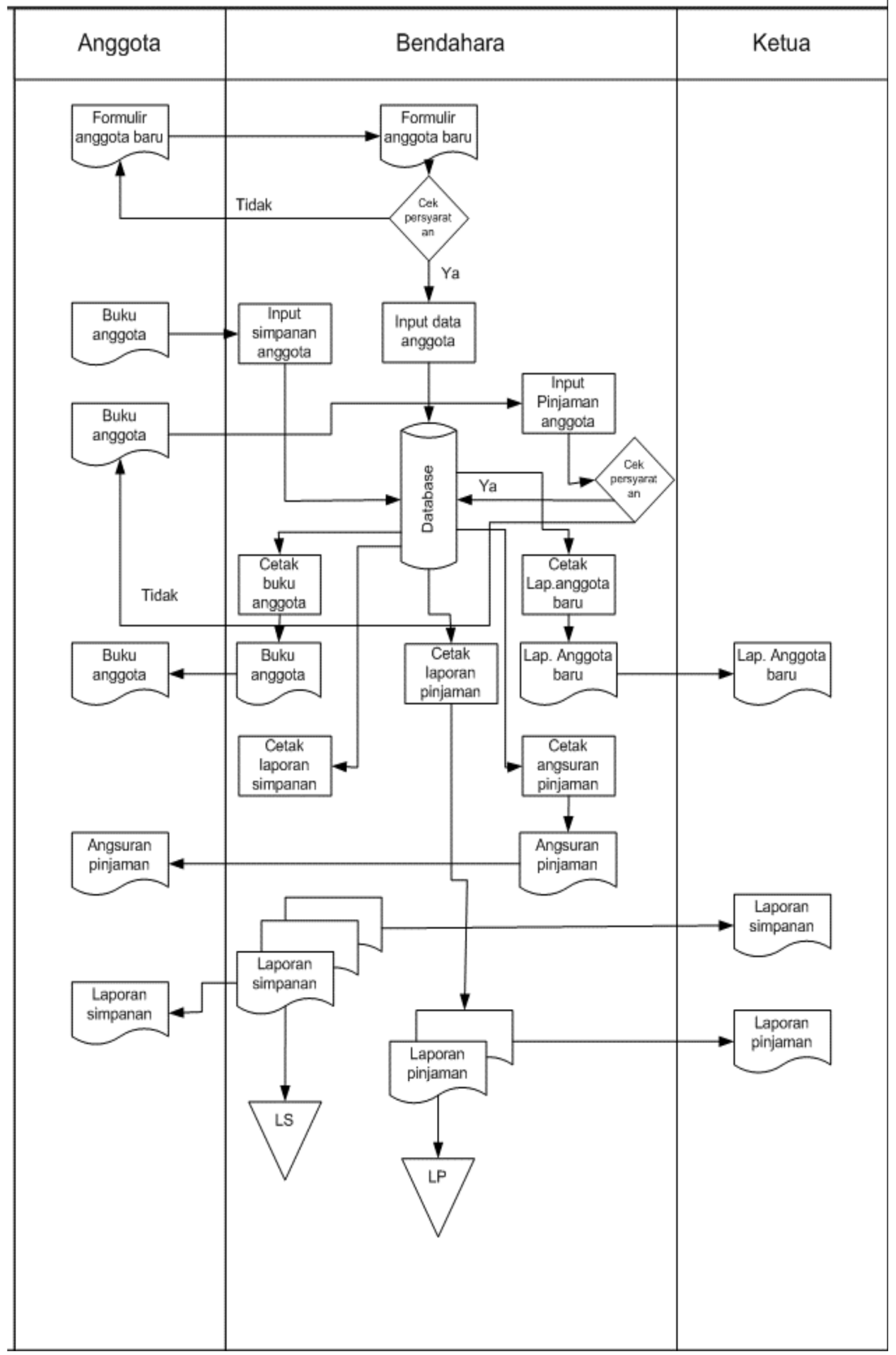

Gambar 3. flowchart sistem yang diusulkan 


\subsection{Pembahasan}

1. Form login

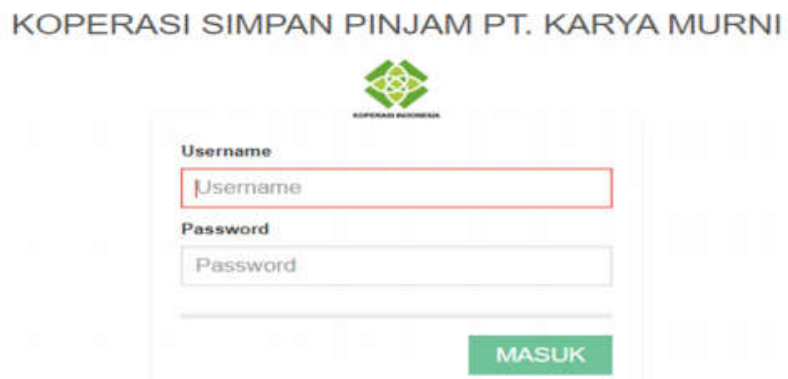

Gambar 4. Form Login

Pada saat program dijalankan, tampilan yang pertama kali muncul adalah form login. Form ini dibuat untuk pengaman agar tidak semua orang dapat menggunakan aplikasi ini. Didalam form login ini akan diminta untuk mengisi username dan password. Apabila username dan password yang diisi benar, maka akan masuk ke menu utama, dan jika salah maka program tidak akan bisa masuk ke menu utama.

\section{Form Administrator}

\section{NASABAH SIMPANAN PINJAMAN LAPORAN PENGATURAN Administrator}

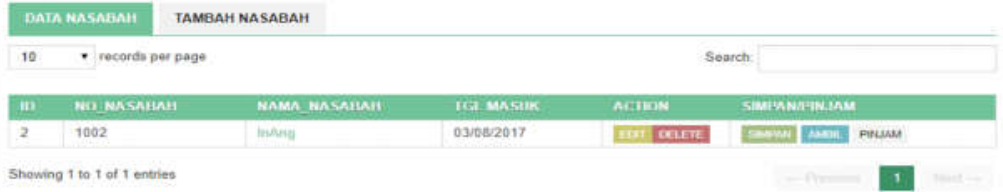

Gambar 5. Form Administrator

Pada tampilan form ini, dapat dilihat menu-menu dan sub menu dalam aplikasi koperasi simpan pinjam Karya Murni. Dalam form ini menampilkan menu-menu yang nantinya akan digunakan dalam aplikasi diantaranya, menu nasabah, menu simpanan, menu pinjaman, menu cicilan, menu denda, menu laporan dan pengaturan.

3. Form Nasabah

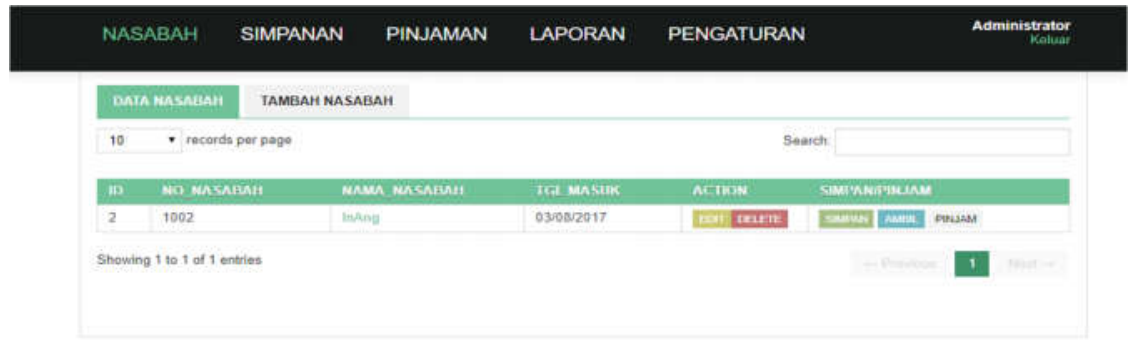

Gambar 6. Form Nasabah

Form ini adalah form yang digunakan untuk mengisi data nasabah baru pada koperasi simpan pinjam Karya Murni. Selain itu, form ini juga berfungsi untuk mengedit dan menghapus data-data nasabah pada koperasi simpan pinjam. 
Jurnal Inkofar * Volume 1 No. 1 Juli 2019 * ISSN: 2615-3645 (Print) / 2581-2920 (Online)

Tersedia secara online di: http://www.politeknikmeta.ac.id/meta/ojs/

4. Form Simpanan

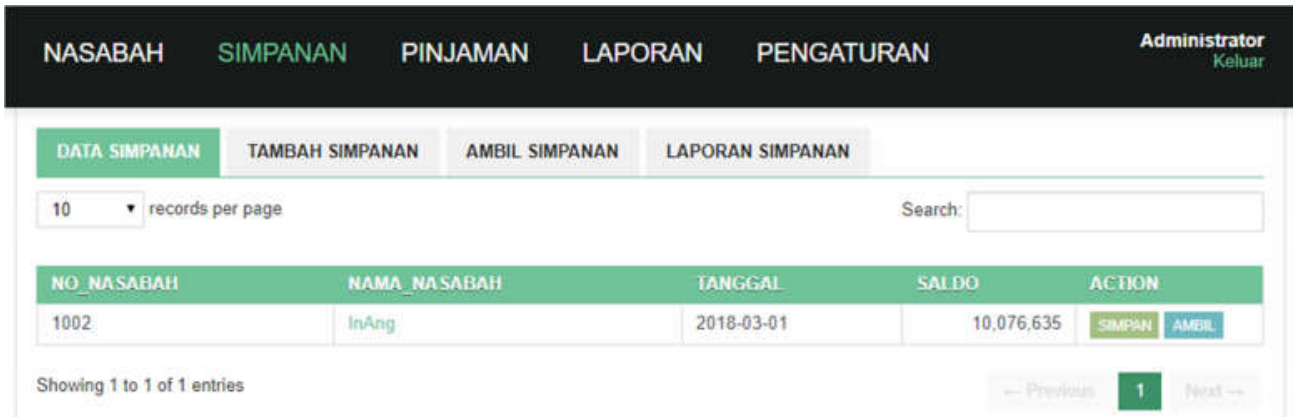

\section{Gambar 7. Form Simpanan}

Form ini adalah form yang digunakan untuk mengisi data simpanan nasabah. Dan juga berfungsi untuk mengedit dan menghapus data-data nasabah, serta laporan nasabah tersebut dapat didownload sebagai bukti transaksi.

5. Form Pinjaman

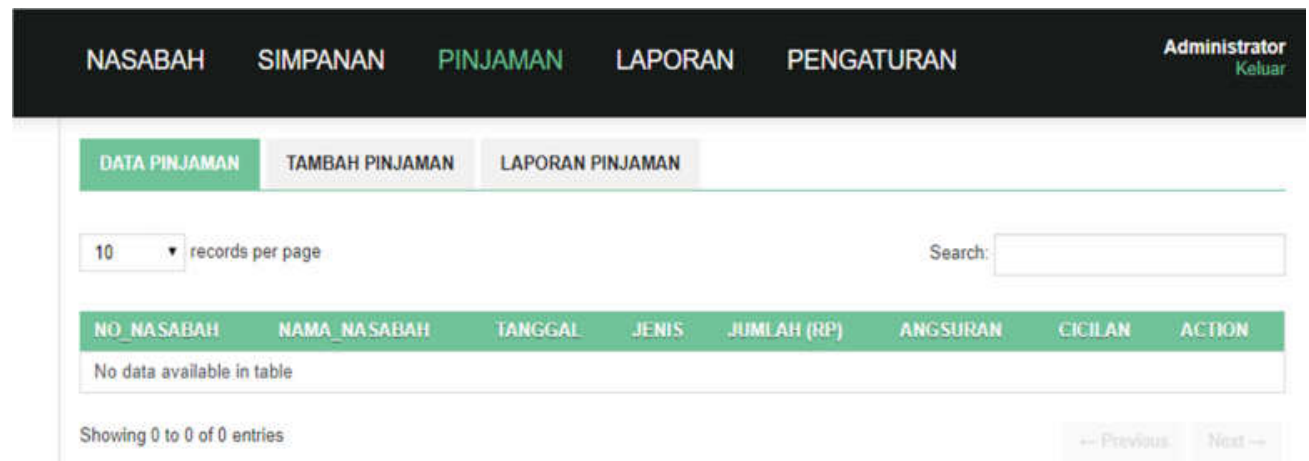

\section{Gambar 8. Form Pinjaman}

Form ini adalah form yang digunakan untuk mengisi data pinjaman nasabah. Dan juga berfungsi untuk mengedit dan menghapus data pinjaman nasabah, serta laporan nasabah tersebut dapat didownload sebagai bukti transaksi.

6. Form Laporan

\section{NASABAH SIMPANAN PINJAMAN LAPORAN PENGATURAN}

\begin{tabular}{|c|c|c|c|c|}
\hline & & PERIODE : & March 2016 & , \\
\hline NO_ANGGOIA & JENIS IRANSAKSI & KEIERAKGAN & TANGGAL & \\
\hline 1002 & simpanan & Pokok & 2016-03-01 & \\
\hline 1002 & simpanan & Sukarela & 2016-03-01 & \\
\hline
\end{tabular}

Gambar 9. Form Laporan

Form ini berisikan tentang laporan transaksi yang terjadi di koperasi simpan pinjam. Di form ini juga dimunculkan nomor anggota, jenis transaksi, keterangan transaksi, dan tanggal transaksi. 
Jurnal Inkofar * Volume 1 No. 1 Juli 2019 * ISSN: 2615-3645 (Print) / 2581-2920 (Online)

Tersedia secara online di: http://www.politeknikmeta.ac.id/meta/ojs/

\section{KESIMPULAN DAN SARAN}

\subsection{Kesimpulan}

Dari pembahasan yang sudah diuraikan maka peneliti mencoba membuat kesimpulan seperti berikut ini:

1. Sistem yang dirancang berbasis web mampu meningkatkan kinerja koperasi simpan pinjam Karya Murni dan dapat diakses kapunpun dan dimanapun.

2. Sistem yang dirancang ini mampu meminimalkan kesalahan dan pengolahan data koperasi simpan pinjam di Koperasi Simpan Pinjam Karya Murni yang dimana pengolahan datanya menjadi terkomputerisasi.

\subsection{Saran}

Berdasarkan penelitian yang peneliti lakukan, adapun saran yang dapat peneliti kemukakan adalah aplikasi yang dirancang masih terdapat kekurangan sehingga rancangan aplikasi yang peneliti rancang dapat dijadikan bahan pertimbangan bagi pihak koperasi simpan pinjam Karya Murni.

\section{DAFTAR PUSTAKA}

S., Rosa dan Shalahuddin, M. 2015. Rekayasa Perangkat Lunk Terstruktur dan Berorientasi Objek. Bandung: Informatika.

Anggoro, Dani. 2015. "Rancangan Sistem Informasi Koperasi Simpan Pinjam Guru dan Pegawai pada Koperasi SMK Manggala Tangerang" dalam Jurnal Seminar Nasional Teknologi Informasi dan Komunikasi 2015 (SENTIKA 2015): Yogyakarta.

Buana, I Komang Setia. 2014. Jago Pemrograman PHP. Jakarta: Dunia Komputer.

Darmawan. 2013. Metode Penelitian Kuantitatif. Bandung: Remaja Rosdakarya.

Kristanto, P. 2013. Ekologi Industri. Yogyakarta: Andi offset.

Madcoms. 2013. Kupas Tuntas Adobe Dreamweaver CS6 dengan Pemrograman PUP dan MySQL. Yogyakarta: Andi

Madcoms. 2016. Pemrograman PHP dan MySQL untuk Pemula. Yogyakarta: Andi.

Simanjuntak, Wanti. 2017. Perancangan Sistem Informasi Simpan Pinjam pada Koperasi Karyawan Jujur Makmur (KKJM). Skripsi. Sekolah Tinggi Manajemen Informatika dan Komputer (STMIK) GICI: Batam. 